\title{
ARTICLE
}

Animal Models

\section{High fat diet causes distinct aberrations in the testicular proteome}

\author{
S. Jarvis ${ }^{1}$ - L. A. Gethings ${ }^{2}$ - L. Samanta $\mathbb{D}^{3,4} \cdot$ S. M. A. Pedroni ${ }^{5} \cdot$ D. J. Withers ${ }^{5,6} \cdot$ N. Gray ${ }^{7} \cdot$ R. S. Plumb ${ }^{8}$ \\ R. M. L. Winston ${ }^{1}$. C. Williamson ${ }^{9}$ - C. L. Bevan ${ }^{1}$
}

Received: 3 October 2019 / Revised: 22 April 2020 / Accepted: 5 May 2020 / Published online: 16 July 2020

(c) The Author(s) 2020. This article is published with open access

\begin{abstract}
Diet has important effects on normal physiology and the potential deleterious effects of high fat diets and obesity on male reproductive health are being increasingly described. We conducted a histological review of the effects of chronic high fat (HF) diet (using a mouse model fed a 45\% fat diet for 21 weeks) with a discovery proteomic study to assess for changes in the abundance of proteins in the testis. Mice on a HF diet became obese and developed glucose intolerance. Using mass spectrometry, we identify 102 proteins affected in the testis of obese mice. These included structural proteins important for the blood testis barrier (filamin A, FLNA), proteins involved in oxidative stress responses (spermatogenesis associated 20, SPATA-20) and lipid homoeostasis (sterol regulatory element-binding protein 2, SREBP2 and apolipoprotein A1, APOA1). In addition, an important regulator protein paraspeckle component 1, PSPC-1, which interacts with the androgen receptor was significantly downregulated. Proteomic data was validated using both Western blotting and immunostaining which confirmed and localised protein expression in both mouse and human testis using biopsy specimens. This study focused mainly on the abnormalities that occurred at the protein level and as a result, we have identified several candidate proteins and conducted pathway analysis around the effects of HF diet on the testis providing novel insights not previously described. Some of the identified targets could be targeted therapeutically and future work is directed in this area.
\end{abstract}

Supplementary information The online version of this article (https:// doi.org/10.1038/s41366-020-0595-6) contains supplementary material, which is available to authorised users.

$\triangle$ S. Jarvis

sheba.jarvis@imperial.ac.uk

1 Department of Surgery and Cancer, Imperial College, Hammersmith Hospital London, London, UK

2 Waters Corporation, Wilmslow, UK

3 American Center for Reproductive Medicine, Cleveland Clinic, 10681 Carnegie Avenue, Desk X11, Cleveland, OH 44195, USA

4 Redox Biology Laboratory, Department of Zoology, School of Life Sciences, Ravenshaw University, Cuttack, Odisha 753003, India

5 MRC London Institute of Medical Sciences, London, United Kingdom

6 Institute of Clinical Sciences, Faculty of Medicine, Imperial College London, London W12 0NN, UK

7 Division of Computational and Systems Medicine, Sir Alexander Fleming Building South Kensington, London SW7 2AZ, UK

8 Waters Corporation, Maple Street, Milford, MA, USA

9 Department of Women and Children's Health, Kings College London, Guys Campus, London, UK

\section{Introduction}

Diet can have a significant impact on normal physiology, with high calorific foods and sedentary lifestyles contributing to the development of obesity, an epidemic in adults, as well as children [1]. Obesity comes with a plethora of adverse health consequences, including cardiovascular diseases, dyslipidaemias, non-alcoholic fatty liver disease and higher incidence of type 2 diabetes and various cancers including female cancers [2-5]. It is also increasingly recognised that being overweight or obese may have a deleterious effects on female fertility [6,7]. Men with higher body mass index (BMI) are more likely to have unfavourable semen parameters with a higher incidence of azoospermia [8-10]. Diets high in saturated fat are negatively correlated with sperm concentration and this has been described to occur in a dose dependent manner [11].

The association between obesity and impaired male reproductive function is multifactorial, involving alterations at the level of the hypothalamic-pituitary-gonadal (HPG) axis, as well as direct testicular effects on spermatogenesis and somatic cell function [12]. Rodent studies which use high fat (HF) diet to induce obesity reveal reductions in sperm volume and motility with a higher percentage of morphologically abnormal 
sperm [13]. Obesity may also increase testicular vulnerability to environmental insults and subfertility from pathophysiological states (e.g., cholestasis) [14-16]. HF diets affects androgen receptor (AR) expression essential for male fertility [17] also causing testicular inflammation, increased oxidative stress causing sperm DNA damage [18, 19]. Effects continue after conception affecting embryo quality and implantation rates [20]. Furthermore, HF diet may also affect the sperm epigenome with trans-generational effects to the offspring of obese males [18, 21].

However, key aberrations in gene targets or pathways in the testis from HF diets are still relatively unknown with modest changes in RNA transcripts in the mouse testis making it challenging to understand pathways by which HF diets exerts such deleterious consequences [18, 22, 23]. Gene expression studies are unlikely to be the most relevant investigation to comprehensively understand the effects of HF on the testis, particularly as male germ cells become transcriptionally silent in late spermatogenesis. At the protein level, one recent study used proteomic analysis in conjunction with long non-coding RNA arrays to study testes from rats fed a HF diet; cytoskeleton changes and oxidative stress were found to be important [24]

Here, we used a discovery approach to study the effects of diet-induced obesity on the testis, generating a valuable proteomic dataset of potential 'hits' providing insight into how obesity may affect specific biological pathways and protein networks in the testis.

\section{Methods}

\section{Animal experiments}

In vivo studies were performed in accordance with the United Kingdom Animals (Scientific Procedures) Act (1986) and Imperial College's Animal Welfare and Ethical Review Body. 3Rs approach was followed in these studies and we obtained testicular tissues from wild type C57BL/6 mice, used for other HF studies [25]. We undertook a comparison of the tissues between male mice randomised to either a diet consisting of $45 \%$ fat (HF) diet (Research Diets, New Brunswick NJ Cat\# D1245) or standard mouse chow (NC) (4.25\% fat, RM3; Special Diet Services) between 11 and 32 weeks of age. They were maintained on a 12-h light/dark cycle with free access to water and housed in specificpathogen free barrier facilities. Testes were isolated, flash frozen in liquid nitrogen and processed for relevant studies.

\section{Human testicular biopsies sample collection}

Human testicular biopsies were obtained from consented patients undergoing microsurgical extraction of sperm
(mTESE) procedures for sperm retrieval (London REC reference 05/q0406/159). Samples were processed for histological assessment and immunofluorescence staining.

\section{Assessment of weight and glycaemic status of mice}

Mice were weighed from 4 weeks of age. At 8 and 27 weeks of age, an intra-peritoneal glucose tolerance test (ipGTT) was performed. After an overnight fast, mice were given an intra-peritoneal injection of glucose $(2 \mathrm{mg} / \mathrm{kg}-20 \%$ $\mathrm{v} / \mathrm{w})$ and blood samples collected from the tail vein immediately prior to the injection (time 0 ) and 15, 30, 60 and 120-minutes after glucose administration.

\section{Histological analysis and immunostaining}

Testicular sections from 4 mice per group were analysed for stereological estimates and immunohistochemistry. Testes were fixed in Bouin's fluid (Sigma Aldrich) or 10\% Neutral buffered formalin (Fisher Scientific) at $4{ }^{\circ} \mathrm{C}$ overnight and treated through graded ethanol and Histoclear (National Diagnostics Ltd) ready for paraffin embedding. Serial sections $(5-6 \mu \mathrm{m})$ were stained with a standard haematoxylin and eosin (H\&E) and counting methods undertaken as previously described to quantitate spermatogenesis [26-29]. In addition, Immunofluorescence and Terminal deoxynucleotidyl transferase staining (TUNEL) staining (Roche, UK) performed with Zeiss 510 confocal microscopy for visualisation (see supplementary methods).

\section{Western blotting}

Whole mouse testes were disrupted in $1 \mathrm{ml}$ of Tissue PE lysis buffer ( $G$ Biosciences) and protease cocktail inhibitor (Sigma) using Qiagen TissueLyser. After protein quantification with appropriate standards (Biorad ${ }^{\mathrm{TM}}$ DC Protein Assay), $10 \mu \mathrm{g}$ protein extract was separated using SDSPAGE. Gels were electroblotted onto Immobilon-P membranes (Millipore) using semi-dry transfer (Bio-Rad TransBlot $\mathrm{SD}^{\circ}$ ). Non-specific binding was blocked using $5 \% \mathrm{w} / \mathrm{v}$ non-fat dried milk diluted in Phosphate Buffered Saline plus $0.05 \%$ Tween-20 (PBS-T). Primary antibodies were mouse monoclonal against $\beta$-actin at [1:5000], filamin A [1:1000], paraspeckle protein-1 [1:1000] (Abcam, Cambridge, MA, USA) and SPATA-20 [1:1000] (Atlas Antibodies). All membrane washes were undertaken with PBS-T. Peroxidase-labelled rabbit anti-mouse and goat anti-rabbit secondary antibodies (Dako, Ely, UK) were used at 1:2000. Membranes were incubated with Luminata Forte Western HRP substrate for $10 \mathrm{~min}$ (Millipore) followed by detection of chemiluminescence and photo acquisition (Fusion Solo, Vilber). 


\section{Preparation of samples for proteomic studies}

Protein extraction protocol Frozen testicular tissue (40 mg) was thawed and placed in pre-chilled bead-beater tubes containing $100 \mu \mathrm{L} 1 \mathrm{~mm}$ zirconium beads. Protein extraction was conducted as previously reported [30]. A Precellys bead beater was used to homogenise the samples at $6,500 \mathrm{~Hz}(2 \times 40 \mathrm{~s}$ cycles $)$, in $100 \mathrm{mM}$ Tris-HCL $(\mathrm{pH}$ 7.6), $100 \mathrm{mM}$ DDT and 4\% SDS lysis buffer and samples incubated at $95^{\circ} \mathrm{C}$ for $3 \mathrm{~min}$, sonicated for $5 \mathrm{~min}$ before centrifugation at $15,000 \times g$ for $10 \mathrm{~min}$ at $20^{\circ} \mathrm{C}$. Supernatant was removed and protein concentration determined prior to analysis using BCA-assay (Thermo Scientific, Loughborough, UK) following the manufacturer's protocol.

Protein digestion Testicular homogenates were diluted to $\sim 1 \mathrm{mg} / \mathrm{ml}$ in $0.1 \%(\mathrm{w} / \mathrm{v})$ RapiGest (Waters Corporation, Milford, USA) in $50 \mathrm{mM}$ ammonium bicarbonate (Sigma Aldrich, St. Louis, MO) and heated at $80^{\circ} \mathrm{C}$ for $45 \mathrm{~min}$. Samples were reduced with $5 \mathrm{mM}$ dithiothreitol (Sigma Aldrich) at $60{ }^{\circ} \mathrm{C}$ for $30 \mathrm{~min}$ and alkylated with $15 \mathrm{mM}$ iodoacetamide (Sigma Aldrich) at room temperature in the dark for $30 \mathrm{~min}$. Proteolytic digestion was undertaken by adding sequencing grade TMPK-treated trypsin gold, mass spectrometry grade (Promega, Madison, MI) at a 1:25 (w/w) ratio and incubation overnight at $37^{\circ} \mathrm{C}$. Trifluoroacetic acid (Sigma Aldrich) was added to a final concentration of $0.5 \%$ (v/v) to hydrolyse the RapiGest and the solutions incubated at $37^{\circ} \mathrm{C}$ for $20 \mathrm{~min}$ before vortexing and centrifugation steps $(10 \mathrm{~min}$ at $10,000 \mathrm{rpm})$. Supernatant was diluted with water containing $0.1 \%(\mathrm{v} / \mathrm{v})$ formic acid.

LC-MS configuration 1D nanoscale LC separation of tryptic peptides was performed with the ACQUITY M Class system (Waters Corporation), configured with a Symmetry C18 $5 \mu \mathrm{m}, 2 \mathrm{~cm} \times 180 \mu \mathrm{m}$ pre-column and an HSS T3 C18 $1.8 \mu \mathrm{m}, 25 \mathrm{~cm} \times 75 \mu \mathrm{m}$ analytical RP column (Waters Corporation). MS analysis of tryptic peptides was performed using a Synapt G2-Si mass spectrometer (Waters Corporation, Wilmslow, UK) (further information given in supplementary methods). Samples were transferred with aqueous $0.1 \%(\mathrm{v} / \mathrm{v})$ formic acid to the precolumn at a flow rate of $5 \mu \mathrm{l} / \mathrm{min}$ for $5 \mathrm{~min}$. Mobile phase A consisted of water containing $0.1 \%(\mathrm{v} / \mathrm{v})$ formic acid, whilst mobile phase B consisted of acetonitrile containing $0.1 \%(\mathrm{v} / \mathrm{v})$ formic acid. After desalting and preconcentration, peptides were eluted from the pre-column to the analytical column with separation using a gradient of $3-40 \%$ mobile phase B for $90 \mathrm{~min}$ (flow rate of $300 \mathrm{nl} / \mathrm{min}$ ), followed by a $2 \mathrm{~min}$ column rinse with $85 \%$ of mobile phase B. Re-equilibration of columns used initial conditions for a $20 \mathrm{~min}$ period. Analytical column temperature was maintained at $35^{\circ} \mathrm{C}$ and lock mass compound, [Glu $\left.{ }^{1}\right]$-Fibrinopeptide B (Sigma-
Aldrich, St Louis, MO)(200 fmol/ $\mu \mathrm{l})$, was delivered by the auxiliary pump of the LC system at $500 \mathrm{nl} / \mathrm{min}$ to the reference sprayer of the NanoLockSpray source of the mass spectrometer. Accurate mass LC-MS data were collected in mobility assisted data independent $\left(\mathrm{LC}-\mathrm{UDMS}^{\mathrm{E}}\right)$ mode of acquisition [31]. MS analysis of tryptic peptides was performed using a Synapt G2-Si mass spectrometer (Waters Corporation, Wilmslow, UK). All analyses were performed in positive mode electrospray ionisation (ESI) and time of flight analyser (ToF) externally calibrated with a NaCsI mixture from $\mathrm{m} / \mathrm{z} 50$ to 1990 . The reference sprayer was sampled with a frequency of $60 \mathrm{~s}$. Accurate mass LC-MS data were collected in mobility assisted data independent $\left(\mathrm{LC} \mathrm{UDMS}{ }^{\mathrm{E}}\right.$ ) mode of acquisition [31].

Progenesis QI for proteomics (Nonlinear Dynamics, Newcastle upon Tyne, UK) was used to peak pick, align, normalise and provide relative quantification from the acquired proteomic data. Protein identifications were obtained by searching the reviewed entries of Mus musculus UniProt database (16,738 entries, release 2016_02). Median abundance normalisation was conducted using a two-group experimental design each consisting of data from 3 mice per group (with 3 technical replicates per samples). Relative protein abundance levels and associated reliability of the measured differences, were considered significant with a minimum fold change of two between both biological groups and an ANOVA $p$-value $\leq 0.05$. Protein identifications were further curated on the basis of replication and accepted if consistently found in $\geq 2$ biological and technical replicates.

Gene ontology (GO) search and protein:protein interactions GO terms were generated for biological and molecular process by uploading the top differentially expressed proteins between the HF and normal chow (NC) fed mice using PantherDB (Protein ANalysis THrough Evolutionary Relationships, version 11) [32]. Protein-protein interactions between differentially expressed proteins in HF conditions were determined using STRING (version 10.5) [33].

Ingenuity pathway analysis (IPA) Ingenuity Pathway Analysis (IPA ${ }^{\circledR}$, QIAGEN Redwood City) was used for pathway analysis and top canonical pathways are presented which were affected by HF diet using Fisher's exact test.

\section{Results}

\section{High fat diet resulted in increased body weight and insulin resistance}

The effects of diet on long-term body weight regulation in male mice fed either a normal chow (NC) or high-fat (HF) diet was studied (Fig. 1a) and mice weight and glucose 
a
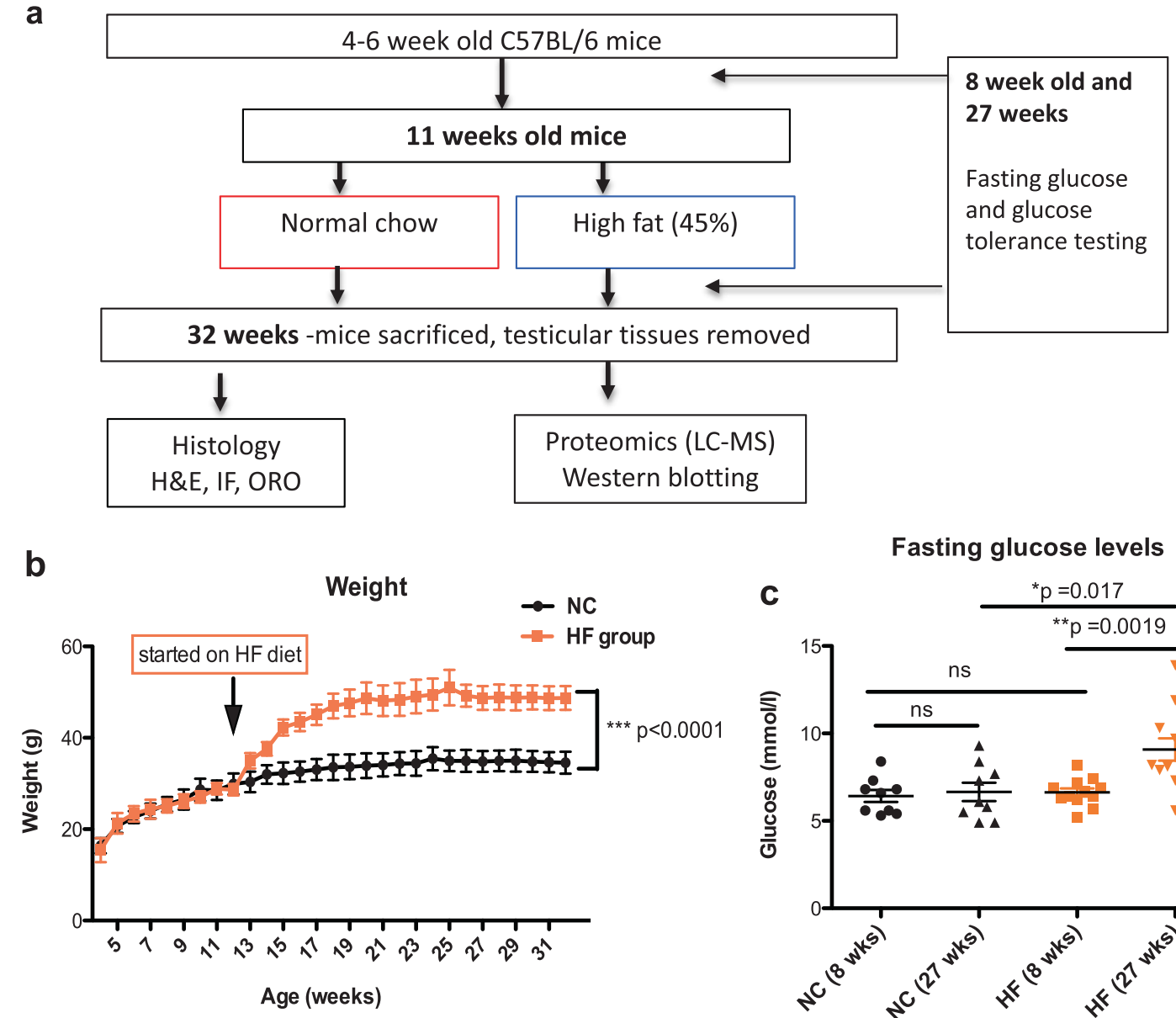

Fasting glucose levels

d

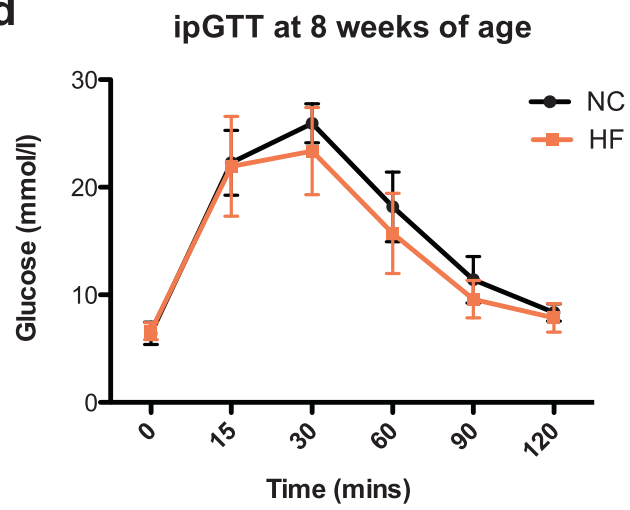

Fig. 1 Effects of the HF diet on body weight and glycaemic control. a Experimental set up and use of tissues. b Body weight. Mice were weighed weekly prior to and after receiving the $\mathrm{HF}(n=9)$ or NC diets $(n=7)$. c Effect of HF diet on fasting glucose when mice were tested at 8 weeks of age when all were on the same diet and then repeated at 27 weeks of age (16 weeks after commencing HF diet) or ongoing NC

tolerance represents further analysis of previously published data [25]. At 11 weeks of age, average body weight for all mice was $28 \pm 2.31 \mathrm{~g}$ (mean $\pm \mathrm{SD})$. High fat $(\mathrm{HF})$ diet was introduced to the experimental group from 11-weeks of age $(n=13$ mice) whilst the control group continued with

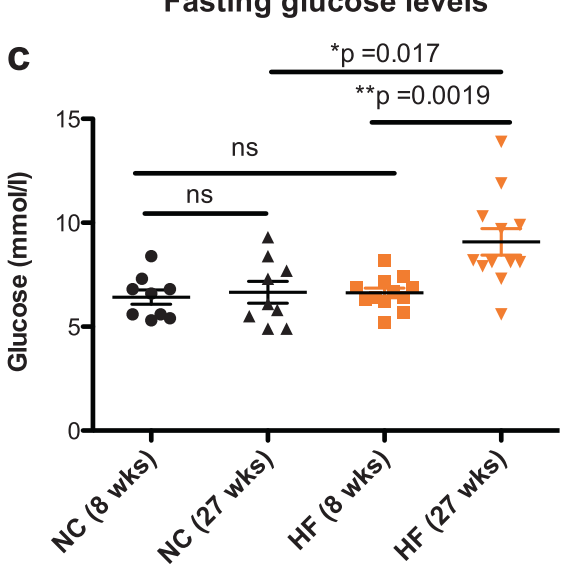

e

ipGTT at 27 weeks of age

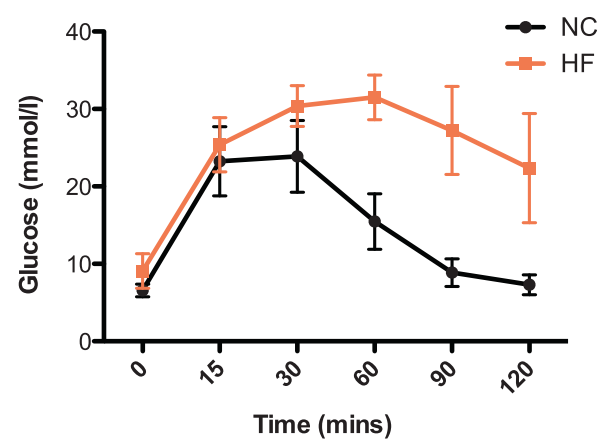

diet. d Effect of HF diet on glucose and (e) glucose tolerance. Statistical analysis performed using 2-way ANOVA $* * * p<0.001 \mathrm{com}$ paring HF to control. Abbreviations Oil red O (ORO), Haematoxylin \& Eosin (H\&E), Immunofluorescence (IF), intraperitoneal glucose tolerance test (ipGTT).

standard normal chow (NC) diet $(n=9)$. After 2 weeks of the $\mathrm{HF}$ diet mice gained $+5.45 \pm 2.34 \mathrm{~g}$, compared to $+1.83 \pm 0.64 \mathrm{~g}$ in the control group. By the end of the study when mice were 32 weeks of age, those on the HF diet were significantly heavier (by $\sim 12 \mathrm{~g}$ ) than those on the $\mathrm{NC}$ diet, 
weighing $46.77 \pm 6.14 \mathrm{~g}$ compared to $34.47 \pm 2.85 \mathrm{~g}$ in the control group $(p<0.0001)$ (Fig. 1b).

Fasting glucose levels were measured before and after mice were exposed to either HF or NC conditions (Fig. 1c). At baseline testing at 8 weeks of age, there were no differences in the fasting glucose levels between mice which remained on $\mathrm{NC}$ diet and those that were subsequently allocated to the HF diet (Fasting glucose levels of $6.42 \pm$ $1.04 \mathrm{mmol} / \mathrm{l}$ and $6.63 \pm 0.79 \mathrm{mmol} / \mathrm{l}$, respectively). At 27 weeks, when mice in the HF group had received 16 weeks of HF diet, this group had significantly higher $(* * p=0.011)$ fasting glucose levels $(9.08 \pm 2.22 \mathrm{mmol} / \mathrm{l})$ compared to mice on the $\mathrm{NC}$ diet $(6.65 \pm 1.58 \mathrm{mmol} / \mathrm{l})$. Intraperitoneal glucose tolerance tests (ipGTT) at the same timepoints showed that there was significant deterioration in glucose tolerance in mice on the HF compared to NC diet $(p<0.0001)$ (Fig. 1d, e), which suggested establishment of the insulin resistance associated with the obesity phenotype.

\section{HF diet alters Sertoli cell and mature germ cells in the testis}

At 32 weeks of age, testicular tissues were collected for histological assessment. The HF experimental group exhibited gross narrowing of the seminiferous tubules $\left({ }^{*} p<0.05\right)$ (Fig. 2). Reduced Sertoli cell numbers, meiotic index and numbers of post-meiotic round spermatids were observed (Supplementary Table 1). Apoptosis was not increased in the tissues from HF mice (Supplementary Fig. 1).

\section{Proteomic data}

We investigated global differences in protein expression between the two experimental conditions. Firstly, unsupervised principal components analysis (PCA) and hierarchal heatmap clustering showed separation between protein signatures of testes acquired from mice on $\mathrm{HF}$ versus NC diets (Fig. 3a, b). In total, 4960 proteins were identified based on a minimum of 1 peptide per protein (identifications have greater specificity using ion mobility as part of the acquisition) and a 1\% FDR. From the identified proteins, 54 were detected only in the testes from mice fed $\mathrm{NC}$ whilst 74 were unique to the testes from mice on the HF diet (Fig. 3c). Quantitative comparison of the remaining proteins expressed in both conditions $(n=4074$ proteins) revealed that $2.2 \%$ of these proteins $(n=102)$ were statistically deregulated by HF diet $(p<0.05)$ with a $\log 2$ fold change between -2.34 and +1.39 (Supplementary Table 2). Protein quantification was performed using only unique peptides per protein. Of the differentially expressed proteins $(n=102), 82 \%$ were downregulated, whilst $18 \%$ were upregulated (Fig. 3d).

All proteins were functionally annotated for GO terms using PANTHER. The distribution of these proteins in relation to GO biological processes is shown (Supplementary Table 3) and revealed clusters of proteins related to meiosis, mitosis and chromosomal segregation. In addition, roles related to catabolism, protein transport and cellular biogenesis were identified.
Fig. 2 Histological alterations in response to $\mathrm{HF}$ diet in the mouse testes. Representative histological images of $\mathrm{H} \& \mathrm{E}$ stained testicular tissues from mice fed either a HF diet (I,iii) as compared to control mice fed a $\mathrm{NC}$ diet (ii, iv) at the end of study (aged 32 weeks). Narrowing of seminiferous tubules is highlighted (black arrow).

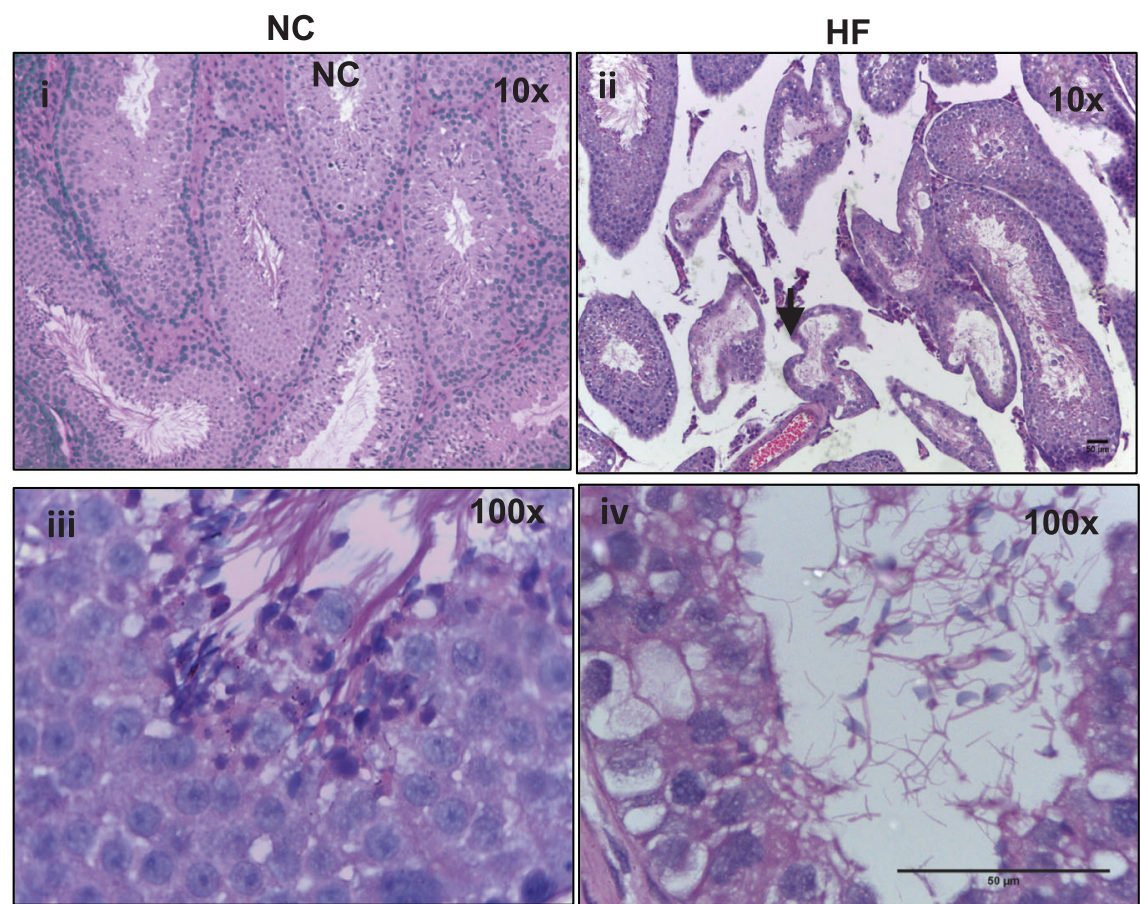



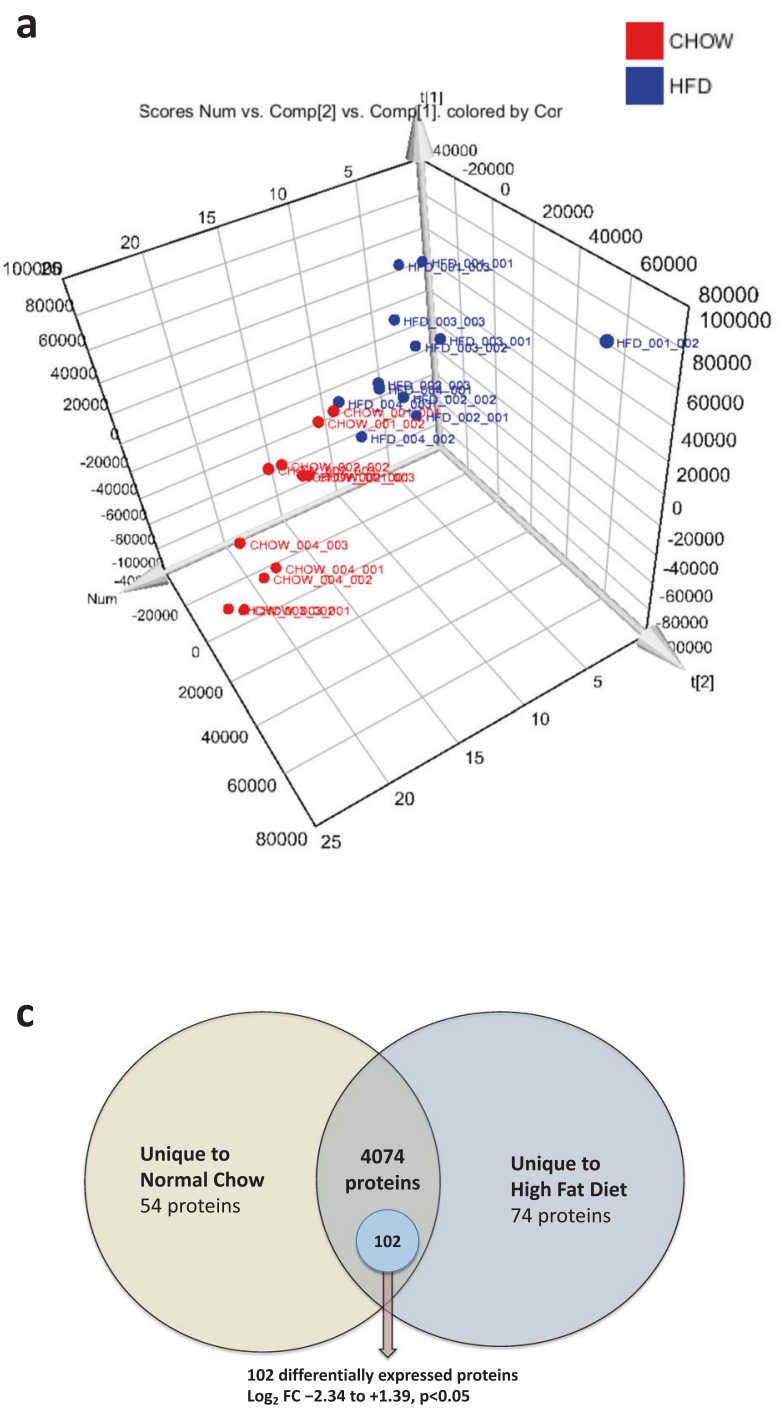

Fig. 3 Summary of proteomic data after multivariate analysis with depiction of differentially expressed proteins in the testes between HF and NC conditions. a Multivariate analysis of proteomic data demonstrating 3D scores plot from unsupervised principal components analysis (PCA) showing separation between the testicular tissues from mice fed a HF diet compared to NC. b Hierarchal cluster heatmap based on protein expression between HFD vs. Chow mice and the contribution to the separation of phenotypes by unique protein IDs to either HF or NC diets. Data is presented as technical triplicates for each mouse sample analysed $(n=3)$. Each lane represents a technical

All protein IDs identified from the mass spectrometry data which were significantly and differentially expressed in the HF diet tissues were converted into protein names using UniprotKB (version 2018_07). In order to understand the biological pathways over represented by these proteins, Ingenuity pathway analysis was undertaken (using the 102 proteins differentially expressed from the HF diet model) (Fig. 4a). The top disrupted pathway in mice fed a HF diet was caveolar mediated endocytosis signalling (Fig. 4b) which had the highest pathway score. Other pathways included epithelial adherens signalling and remodelling,

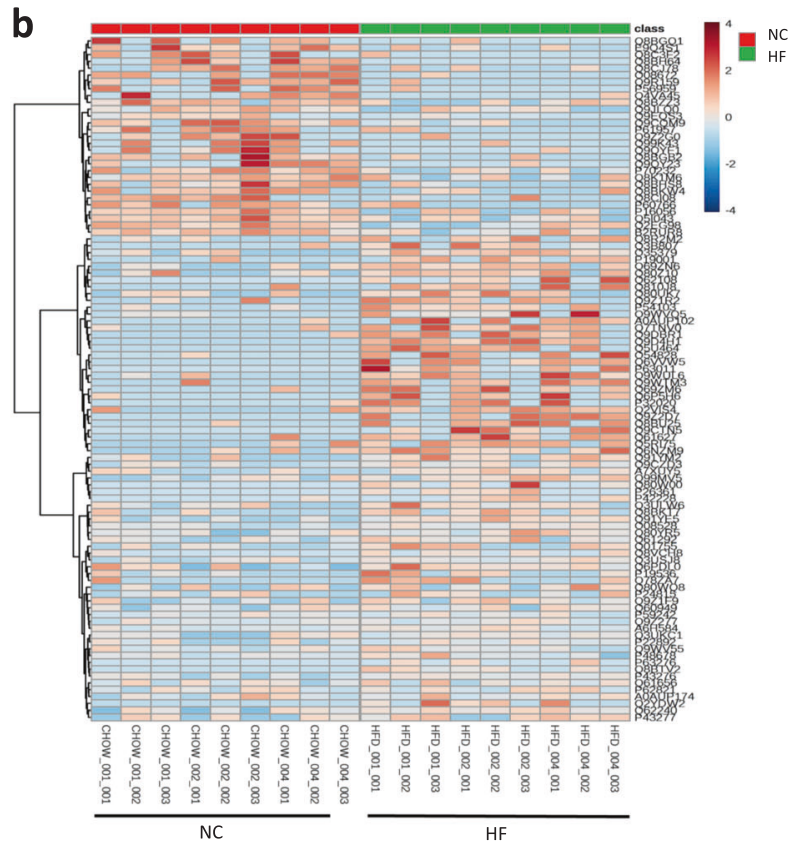

d

\section{Differentially expressed proteins in HF diet model}

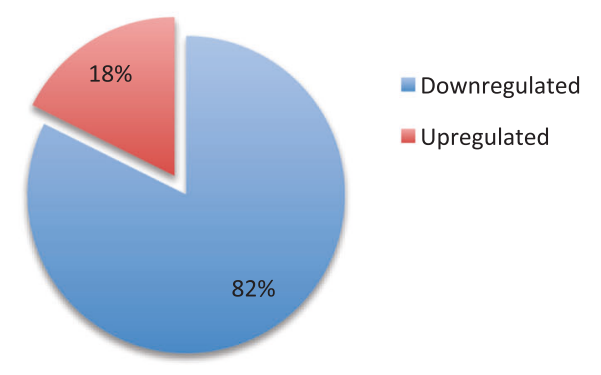

triplicate (Created in Metaboanalyst v3.0). c Venn diagram representation of proteins in the testis between the HF and NC conditions. 1012 proteins were found uniquely in NC mouse testes whilst 920 were uniquely in HF mice. 3028 proteins were expressed in both conditions of which 102 proteins were significantly altered in $\mathrm{HF}$ testes. The $\log 2 \mathrm{FC}$ fold change for these 102 proteins ranged between -2.34 and $1.39(p<0.05)$. d Direction of the differentially expressed statistically significant proteins in HF condition $(n=102$ proteins).

protein kinase A and Rho GDI signalling. Testis-specific pathways disrupted in mice fed a HF diet included Germ cell:Sertoli cell junction signalling and Sertoli:Sertoli cell signalling. Also, sperm motility proteins were disrupted but this fell outside of the top 20 disrupted pathways.

A protein-protein interaction network was constructed using the STRING database. Network analysis confirmed that a large proportion of the 102 differentially expressed proteins altered by HF diet were functionally connected and that the network of proteins had significantly more interactions than would be expected by chance $(P$ value $=0.0036)($ Supplementary Fig. 2$)$. 
a

Pathways associated with altered proteins in $\mathrm{HF}$ mice

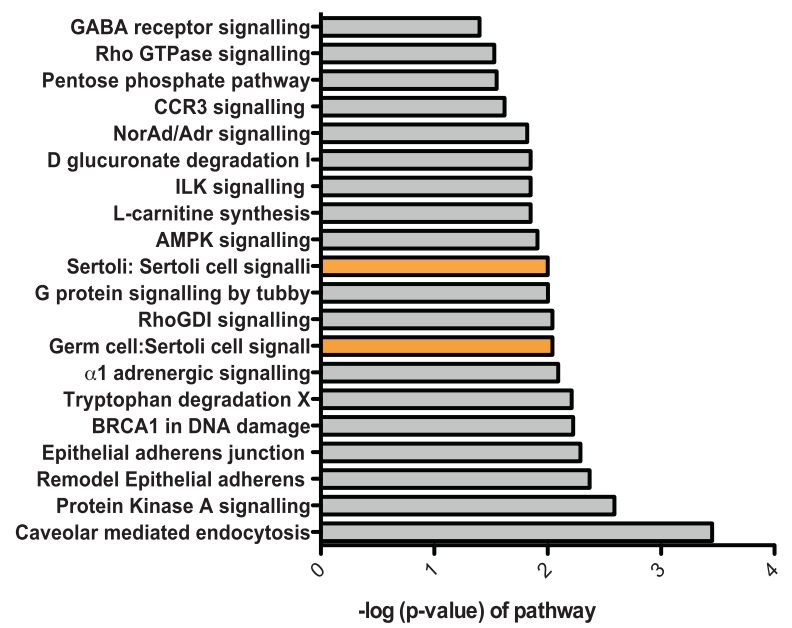

Top pathway altered by HF diet Caveolar mediated endocytosis signalling

b

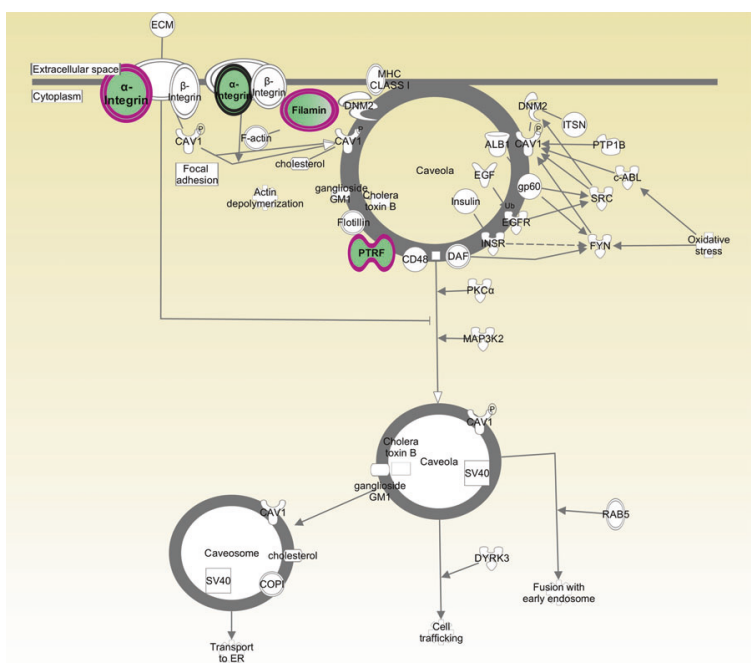

Fig. 4 Top IPA pathways deregulated in the testes in HF diet versus NC conditions. a Top Ingenuity pathways associated with altered proteins in the testes from mice fed a HF diet as compared to NC mice. Bars indicate the likelihood $[-\log (P$-value $)]$ that the specific pathway is affected by dietary fat. Protein IDs generated after LCMS/MS analysis of the global testicular proteome in HF and NC fed mice were put through IPA to generate a total number of curated proteins relevant to that pathway identified in the whole testis. The $p$ value represents the pathway significance to the tissue. Testis specific pathways related to Germ cell-Sertoli cell junction signalling; Germ cell:Germ cell signalling are highlighted in orange. b Top pathway downregulated in testis from HF conditions: caveolar mediated endocytosis signalling, green depicts downregulated proteins in the pathway including FILAMIN A, FILAMIN B, ITGA11 (alpha integrin subunit 11), PTRF/CAV1 (caveolae associated protein).

\section{Validation of proteomic data}

To validate the proteomic data, Western blotting was undertaken using testicular protein lysates from the same mice used for proteomic experiments [34]. Proteins chosen for validation were selected on the basis of (i) magnitude of fold change and (ii) likely biological relevance to fertility. Five proteins altered by HF diet from the proteomic dataset were selected (paraspeckle component 1 [PSPC-1], sterol regulatory element-binding protein 2 [SREBP2], filamin A [FLNA], apolipoprotein A1 [APOA1] spermatogenesis associated 20 [SPATA-20]) (Supplementary Table 4).

Western blots analysis confirmed downregulation of SREBP2 and APOA, FLNA and PSPC-1 (Fig. 5). Previous studies have shown that androgen receptor (AR) is downregulated in testis in the context of HF conditions [17]. We also confirmed reduced AR in the HF conditions by Western blotting, although this was not statistically significant by band densitometry.

Lastly, SPATA-20, thioredoxin-like protein was investigated as an important protein upregulated in testicular oxidative stress (associated with HF diet and obesity) with increase in SPATA-20 noted thus validating LC-MS proteomic findings (Fig. 5).

Next, immunolocalization was used to gauge the expression of the proteins FLNA, PSPC1, SREBP2 in the various testicular compartments or cell types (Fig. 6). FLNA was highly expressed in the cytoplasm of peritubular myoid cells, as well as expressed in elongating spermatids. PSPC-1 was expressed solely in germ cells notably in spermatocytes and round spermatids nuclei. The transcription factor, SREBP2 was expressed in the nuclei of somatic cells (Sertoli cell and Leydig cell nuclei) and in the cytoplasm of spermatocytes, round and elongating spermatids. Comparisons of immunostaining intensity between tissues from NC and $\mathrm{HF}$ mice revealed lower staining intensity of anti-FLNA in germ cells from the testis of HF mice compared to NC. In addition, testicular tissues from mice on HF had fewer PSPC-1 positive stained germ cells with smaller sized foci within the nuclei when compared to testis from mice on NC diet. Finally, a decreased staining intensity of SREBP2 was observed in HF diet tissues correlating with Western blot findings.

\section{Proteins altered by the HF diet are also expressed in the human testis}

To ascertain whether the selected protein targets (FLNA, SREBP2, PSPC1) were expressed in the human testis and whether the same immunolocalisation pattern are observed, testicular samples were obtained from men undergoing testicular biopsy who either had complete spermatogenesis (CS) or had no germ cells present (Sertoli cell only, SCO). We confirmed the expression of FLNA, SREBP2 and PSPC-1 in human testicular tissues using the same antibodies which cross react with both species. The same staining patterns were seen as those in mouse testis suggesting expression within the same testicular cell types. In addition, staining patterns were fairly consistent using 


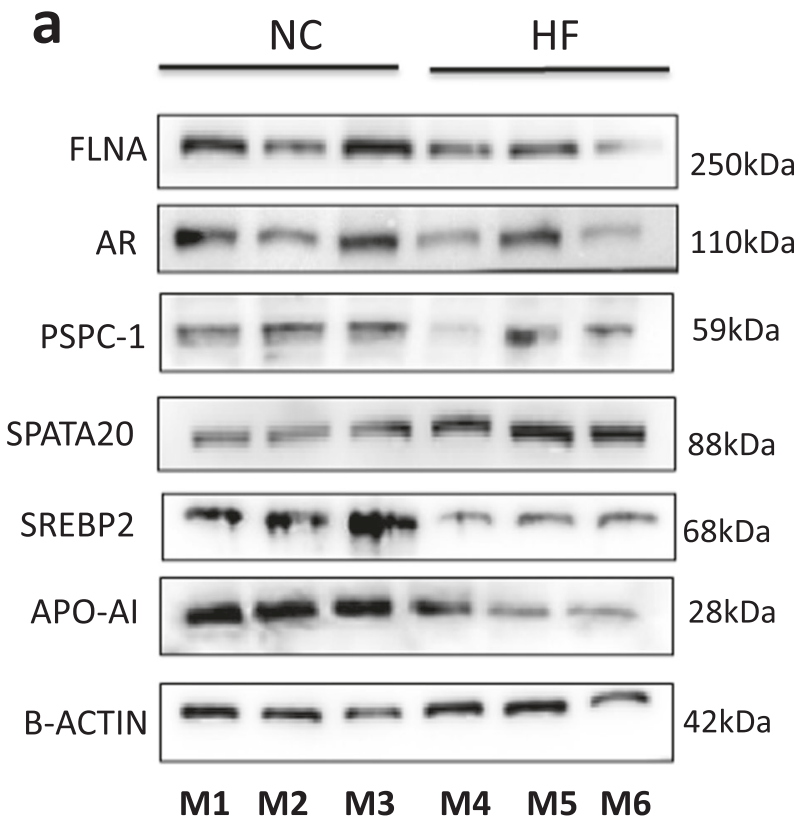

b

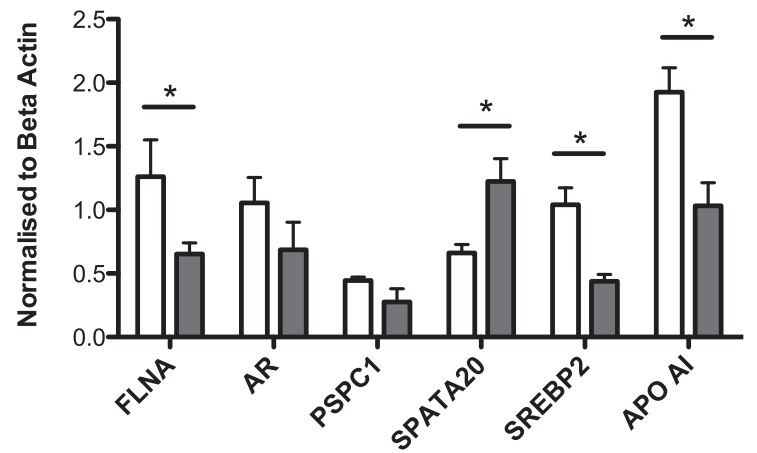

Fig. 5 Western blot validation studies of 6 key protein targets differentially expressed in the testes from mice on $\mathrm{HF}$ diet versus NC conditions. a HF diet decreases the protein expression of FLNA, AR and PSPC-1, SREBP2, APOA-I with an increased in SPATA20 expression. b Western blots of all proteins extracted from testicular tissues from 3 representative mice and (c) semi-quantitative protein expression using band densitometry analysis using image $\mathrm{J}$. Values are average $+/-\operatorname{SEM}(n=3$ per group). $* p<0.05$, $* * p<0.01$, $* * * p<$ 0.001 and compared using by two tailed unpaired $t$ test.

human testicular samples which were compared to the Human Protein Atlas repository (Fig. 6b).

In patients with CS, SREBP2 was expressed both in Sertoli and germ cells. In SCO samples, SREBP2 staining persisted in the nuclei of Sertoli cells. FLNA was observed in human germ cells of the CS samples but no staining was seen in SCO samples where no germ cells exist. Finally, PSPC-1 staining was also observed as paraspeckles within the germ cell nuclei of human CS samples and as expected for this germ cell-specific marker, no PSPC-1 expression was detected in SCO samples. Together, these experiments confirmed that in normal human testicular tissue (CS samples), FLNA, PSPC-1 and SREBP2 are expressed in the same cell types as observed in the mouse testis suggesting possible conserved roles for these proteins in both species.

\section{Discussion}

There is an increasing prevalence of obesity in children and adults, and high consumption of dietary fats are associated with alterations in male fertility and hormonal dysregulation. High BMI is associated with low total sperm count [35] and around $65 \%$ of men with infertility have hyperlipidaemia [36]. It is also known that sperm volume and motility can be affected by elevated total cholesterol and low density lipoprotein [37]. Together, these observations suggest that abnormal lipid metabolism in the male reproductive system can affect fertility

The effects of high fat or obesity on semen parameters are increasingly described but the effects on the testis, an organ exquisitely sensitive to even subtle changes of whole body metabolism, has not been thoroughly studied [38] and key players and biological pathways remain elusive. Molecular perturbations within the testis in diet-induced obesity rodent models have been studied at the transcriptome level with modest changes in gene expression and effects on microRNAs and sperm epigenome [18, 22]. Another study of the rat testicular proteome in conjunction with long non-coding RNAs from HF diet has been published, with pathways relevant to cytoskeleton remodelling and anti-oxidative functions described [24]. A discovery study as described here, where careful histological assessment with the integration of proteomic data can provide greater insight into the consequences of HF diet.

Histological assessment confirmed marked distortion of the seminiferous tubules in the chronic HF diet-fed mice with a reduction in germ cell numbers, particularly spermatogonial stem cells and maturing spermatids with effects on meiotic index. The number of Sertoli cells, crucial for germ cell sustenance were reduced. Therefore, HF diet does not only impact germ cell development but also has an effect on Sertoli cells and the two are likely to be interrelated. A review of the proteomic data has provided insight into the biological pathways affected by HF diet in the testis. Since proteins do not function alone, a protein-protein interaction analysis showed high interaction scores suggesting engagement in a network of proteins with overlapping functions. IPA pathway analysis helped to identify the key roles of these proteins and further analysis of canonical pathways revealed the top deregulated pathways related to 'cavelolar-mediated endocytosis signalling', 
Fig. 6 Immunofluorescence imaging comparing altered protein targets (FLNA, PSPC-

1, SREBP2) between representative testes from mice fed NC and HF diet and expression in human testis.

Representative

immunofluorescence images comparing altered protein targets (FLNA, PSPC-1, SREBP2) between representative testes from (a) mice fed $\mathrm{NC}$ and $\mathrm{HF}$ Mouse testis. All images at presented at $\times 63$, scale bar represents $50 \mu \mathrm{m}$

b Representative

immunofluorescence staining of selected protein targets in human testicular biopsies (from patients with complete spermatogenesis (iv-vi) and Sertoli cell only (vii-ix) compared to images from Human Protein Atlas (i-iii) and mouse testis ( $\mathrm{x}-\mathrm{xii})$. All images at $\times 20$ and scale bar represents $50 \mu \mathrm{m}$. a
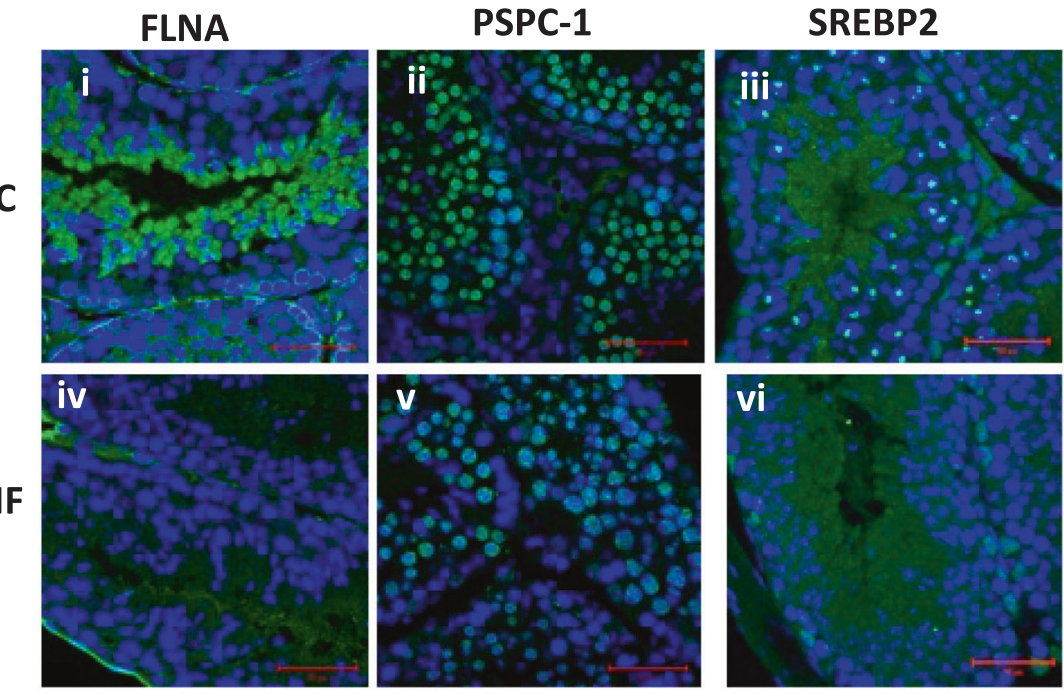

b FLNA
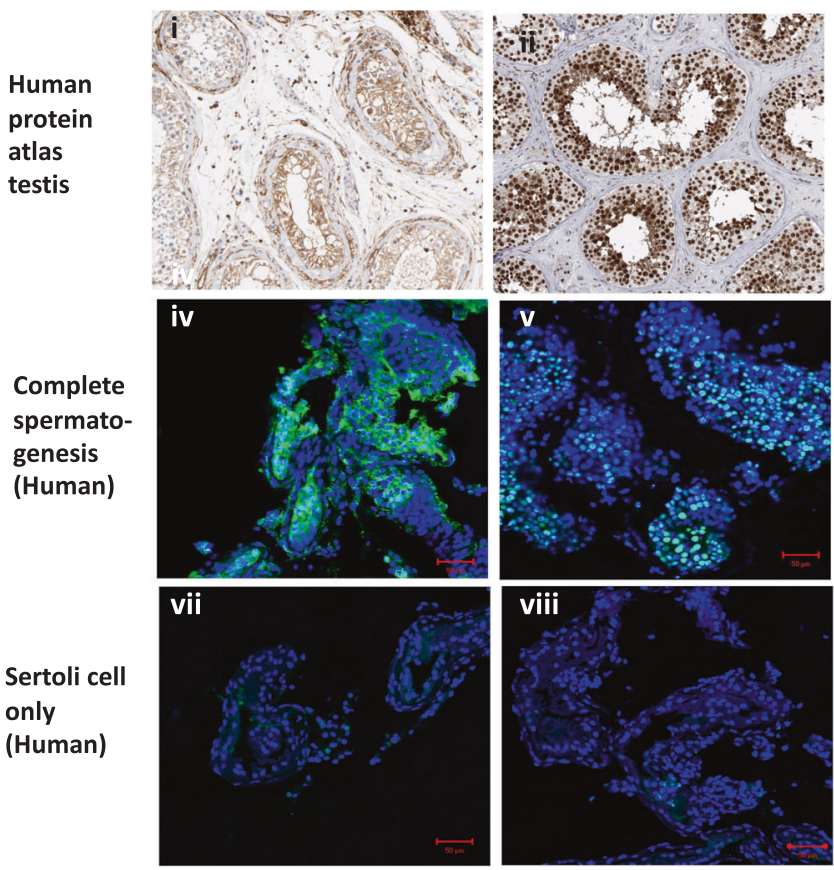

SREBP2
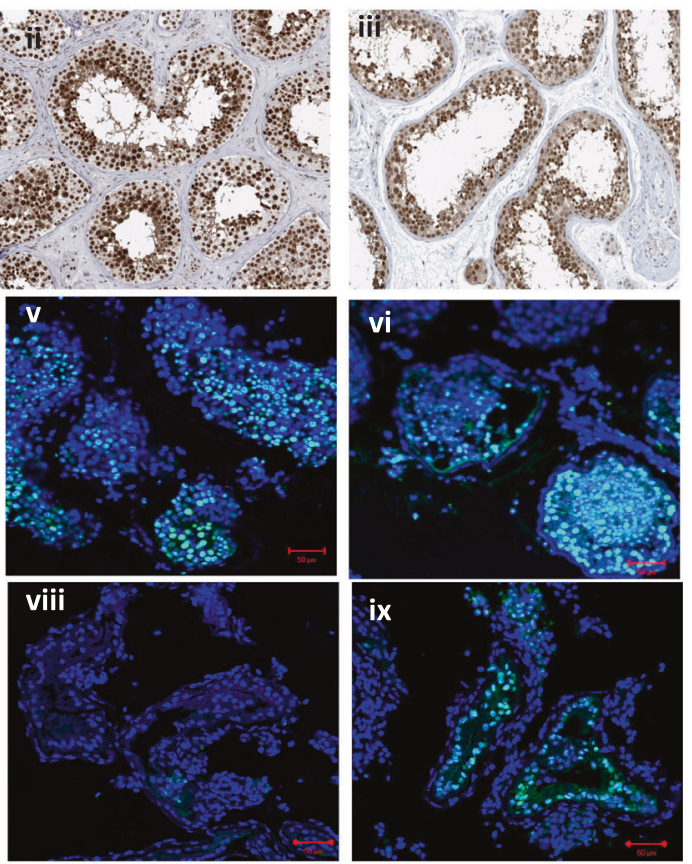

as well as effects on 'Sertoli: germ cell signalling'. These pathways have particular relevance to the blood testis barrier (BTB), an androgen-regulated structure which is disrupted in animals exposed to a $\mathrm{HF}$ diet [17, 39].

The BTB divides the seminiferous tubules into a basal compartment (where early spermatogonia reside) and an adluminal compartment where post-meiotic cells are protected from toxic insults and secluded from the immune system [40]. The BTB forms a complex network of proteins acting as tight junctions (TJ) and gap junctions, together with desmosomes, integral membrane adaptor and cytoskeletal proteins. The BTB is dynamic as germ cells move between the two compartments with the assembly of a new
'BTB' [41] partly dependent on internalisation and recycling of integral membrane proteins using caveolarmediated endocytosis. Since caveolae-associated protein 1 (PTRF/CAV1), filamins A/B and integrin alpha 11 were all significantly downregulated for mice on HF diet, we propose that these specific proteins are implicated in the disruption of the testicular junction. The consequences of this may affect the availability/recycling of proteins at the BTB and impact proper development of germ cells at later stages, in support of which a decline in germ cell numbers was also noted for mice on HF diet.

Although mass spectrometry is a powerful and insightful technique, the experiments conducted here were only 
focused on providing qualitative and quantitative information at the protein/peptide level. Additional information related to post-translational modifications and protein turnover for example, were not accounted for in the scope of this work. Complimentary Western blot studies were conducted on selected key proteins for further validation, based on the magnitude of fold change (compared to control mice), novelty and relevance to human testicular biology. All selected targets (AR, PSPC1, FLNA, APOAI, SREBP2) had conserved expression across species with high expression levels in both mouse and human testicular tissues, and similar immunolocalisation patterns.

Firstly, we were interested in the filamin family (subtypes filamin A, B and C) regulators of the developing BTB in the postnatal testis which form a crucial link between the cellular cytoskeleton and extracellular matrix and found in cell: cell junctions of endothelial cells and in those undergoing polarisation [42]. Filamins have a number of different biological roles with both filamin A and B downregulated in the testis of mice on HF diet. In the adult testis, filamin A and $\mathrm{B}$ are reported to be localised to the basal compartment [43] and important for caveolar-mediated endocytosis of TJ proteins at the BTB and in axonemal formation during ciliogenesis [40, 44-46]. Given that developing spermatids start to polarise and form an axoneme as part of the sperm tail, filamins may have a role here supported by the stage specific expression of filamin A in developing spermatids, and it was in this distribution where much of the filamin A signal was lost in the HF model.

Other proteins that interact with filamin A, include the AR and nephrocystin 4 (NPHP4) and we found in HF conditions, a significant decrease in filamin interacting protein NPHP4, important for cytoskeleton signalling, cell adhesion and ciliary development [47] and associated with human male infertility [48]. Filamin A also interacts with $\mathrm{AR}$, facilitating its nuclear translocation and transactivation; it can also disrupt AR interdomain interactions [49, 50]. Downregulation of AR in mice fed a HF diet has been previously described and is required for normal fertility $[17,51]$. In mice on $\mathrm{HF}$ diet, we find reduced testicular expression of AR and AR coactivator, PSPC-1 [52] which is expressed in nuclear paraspeckles as part of an interaction complex with other proteins acting as AR co-regulators in mouse Sertoli cells [52, 53]. Here in HF diet mice, reduced expression of PSPC-1 was observed in Sertoli cells, as well as stage specific expression of PSPC-1 in spermatocytes and round spermatids, which do not express AR. The role of PSPC-1 in these cell types has yet to be elucidated but may be engaged in gene regulation via RNA processing and DNA repair, and acting synergistically with many other transcription factors.

The final proteomic target selected for validation was SPATA-20 (also referred to as SSP411), a thioredoxin-like protein expressed in spermatids [54] and Ssp411-/- mice have reduced sperm numbers, motility and abnormal sperm morphology [55]. Thioredoxins catalyse protein disulphide bonds and regulate enzymes involved in antioxidant defence and transcription factors. SPATA-20 expression is increased 5 -fold in spermatogenic cells from patients with type 1 diabetes, where a deregulation of oxidative genes is noted when compared to healthy controls [56]. SPATA-20 may have a protective role in sperm likely in the context of sperm oxidative stress which is well associated obesity [19]. In our study, increased SPATA-20 may represent a compensatory response to the potential oxidative stress of HF diet.

In summary, we used a high fat diet model that is representative of human fertility than genetic mouse models. This study focused mainly on the abnormalities that occurred at the protein level and as a result, we have identified several candidate proteins and conducted pathway analysis around the effects of HF diet on the testis providing novel insights not previously described. This is tissue level data and some changes in proteins may be due to a reduced number of a particular cell type and may warrant further interrogation to study specific cell types.

Here we show that many of the identified targets are also expressed in the human testis, it is possible that similar candidates are involved in human infertility and targets such as SREBP2 may be targeted therapeutically by readily available drugs such as metformin [57]. Our work provides a foundation for understanding how obesity may affect male fertility and future functional studies should be directed towards providing support for these potential players.

Acknowledgements This work was funded by a Wellcome Trust Clinical PhD fellowship and a Genesis Research Trust Grant to SJ. DJW was funded from the Medical Research Council (MC-A6545QB40) and a Wellcome Trust Strategic Award (098565).

\section{Compliance with ethical standards}

Conflict of interest The authors declare that they have no conflict of interest.

Publisher's note Springer Nature remains neutral with regard to jurisdictional claims in published maps and institutional affiliations.

Open Access This article is licensed under a Creative Commons Attribution 4.0 International License, which permits use, sharing, adaptation, distribution and reproduction in any medium or format, as long as you give appropriate credit to the original author(s) and the source, provide a link to the Creative Commons license, and indicate if changes were made. The images or other third party material in this article are included in the article's Creative Commons license, unless indicated otherwise in a credit line to the material. If material is not included in the article's Creative Commons license and your intended use is not permitted by statutory regulation or exceeds the permitted use, you will need to obtain permission directly from the copyright holder. To view a copy of this license, visit http://creativecommons. org/licenses/by/4.0/. 


\section{References}

1. NCD Risk Factor Collaboration (NCD-RisC)Worldwide trends in body-mass index, underweight, overweight, and obesity from 1975 to 2016: a pooled analysis of 2416 population-based measurement studies in 128.9 million children, adolescents, and adults. Lancet. 2017;390:2627-42.

2. Johnson W, Li L, Kuh D, Hardy R. How has the age-related process of overweight or obesity development changed over time? co-ordinated analyses of individual participant data from five United Kingdom birth cohorts. PLoS Med. 2015;12:e1001828.

3. Abdullah A, Peeters A, de Courten M, Stoelwinder J. The magnitude of association between overweight and obesity and the risk of diabetes: a meta-analysis of prospective cohort studies. Diabetes Res Clin Pract. 2010;89:309-19.

4. Park J, Morley TS, Kim M, Clegg DJ, Scherer PE. Obesity and cancer-mechanisms underlying tumour progression and recurrence. Nat Rev Endocrinol. 2014;10:455-65.

5. Foong KW, Bolton H. Obesity and ovarian cancer risk: a systematic review. Post Reprod Health. 2017;23:183-98.

6. Gesink Law DC, Maclehose RF, Longnecker MP. Obesity and time to pregnancy. Hum Reprod. 2007;22:414-20.

7. Zain MM, Norman RJ. Impact of obesity on female fertility and fertility treatment. Womens Health. 2008;4:183-94.

8. Chavarro JE, Toth TL, Wright DL, Meeker JD, Hauser R. Body mass index in relation to semen quality, sperm DNA integrity, and serum reproductive hormone levels among men attending an infertility clinic. Fertil Steril. 2010;93:2222-31.

9. Paasch U, Grunewald S, Kratzsch J, Glander H-J. Obesity and age affect male fertility potential. Fertil Steril. 2010;94:2898-901.

10. Luque EM, Tissera A, Gaggino MP, Molina RI, Mangeaud A, Vincenti LM, et al. Body mass index and human sperm quality: neither one extreme nor the other. Reprod Fertil Dev. 2015. https://doi.org/10.1071/RD15351.

11. Jensen TK, Heitmann BL, Blomberg Jensen M, Halldorsson TI, Andersson A-M, Skakkebæk NE, et al. High dietary intake of saturated fat is associated with reduced semen quality among 701 young Danish men from the general population. Am J Clin Nutr. 2013;97:411-8.

12. Sermondade N, Faure C, Fezeu L, Shayeb AG, Bonde JP, Jensen TK, et al. BMI in relation to sperm count: an updated systematic review and collaborative meta-analysis. Hum Reprod Update. 2013;19:221-31.

13. Saez Lancellotti TE, Boarelli PV, Monclus MA, Cabrillana ME, Clementi MA, Espínola LS, et al. Hypercholesterolemia impaired sperm functionality in rabbits. PLoS ONE. 2010;5:e13457.

14. Ghanayem BI, Bai R, Kissling GE, Travlos G, Hoffler U. Dietinduced obesity in male mice is associated with reduced fertility and potentiation of acrylamide-induced reproductive toxicity. Biol Reprod. 2010;82:96-104.

15. Gutzkow KB, Duale N, Danielsen T, von Stedingk H, Shahzadi S, Instanes $\mathrm{C}$, et al. Enhanced susceptibility of obese mice to glycidamide-induced sperm chromatin damage without increased oxidative stress. Andrology. 2016;4:1102-14.

16. Vega A, Martinot E, Baptissart M, De Haze A, Vaz F, Kulik W, et al. Bile acid alters male mouse fertility in metabolic syndrome context. PLoS ONE. 2015;10:e0139946.

17. Fan Y, Liu Y, Xue K, Gu G, Fan W, Xu Y, et al. Diet-induced obesity in male C57BL/6 mice decreases fertility as a consequence of disrupted blood-testis barrier. PLoS ONE. 2015;10:e0120775.

18. Fullston T, Ohlsson Teague EMC, Palmer NO, DeBlasio MJ, Mitchell M, Corbett M, et al. Paternal obesity initiates metabolic disturbances in two generations of mice with incomplete penetrance to the F2 generation and alters the transcriptional profile of testis and sperm microRNA content. FASEB J. 2013;27:4226-43.
19. Bisht S, Faiq M, Tolahunase M, Dada R. Oxidative stress and male infertility. Nat Rev Urol. 2017;14:470-85.

20. Aitken RJ, Koopman P, Lewis SEM. Seeds of concern. Nature. 2004;432:48-52.

21. Fullston T, McPherson NO, Owens JA, Kang WX, Sandeman LY, Lane M. Paternal obesity induces metabolic and sperm disturbances in male offspring that are exacerbated by their exposure to an "obesogenic" diet. Physiol Rep. 2015;3. https://doi.org/10. $14814 /$ phy2.12336.

22. Grandjean V, Fourré S, De Abreu DAF, Derieppe M-A, Remy J-J, Rassoulzadegan M. RNA-mediated paternal heredity of dietinduced obesity and metabolic disorders. Sci Rep. 2015;5:18193.

23. An T, Zhang T, Teng F, Zuo J-C, Pan Y-Y, Liu Y-F, et al. Long non-coding RNAs could act as vectors for paternal heredity of high fat diet-induced obesity. Oncotarget. 2017;8:47876-89.

24. Yang X-Y, Gu Y-J, An T, Liu J-X, Pan Y-Y, Mo F-F, et al. Proteomics analysis of testis of rats fed a high-fat diet. Cell Physiol Biochem. 2018;47:378-89.

25. Smith MA, Katsouri L, Irvine EE, Hankir MK, Pedroni SMA, Voshol PJ, et al. Ribosomal S6K1 in POMC and agrp neurons regulates glucose homeostasis but not feeding behavior in mice. Cell Rep. 2015;11:335-43.

26. Russell LD, Clermont Y. Degeneration of germ cells in normal, hypophysectomized and hormone treated hypophysectomized rats. Anat Rec. 1977;187:347-66.

27. Abercrombie M. Estimation of nuclear population from microtome sections. Anat Rec. 1946;94:239-47.

28. Amann RP. Reproductive capacity of dairy bulls. IV. Spermatogenesis and testicular germ cell degeneration. Am J Anat. 1962;110:69-78.

29. Segatelli TM, França LR, Pinheiro PFF, Alemida CCD, Martinez M, Martinez FE. Spermatogenic cycle length and spermatogenic efficiency in the gerbil (Meriones unguiculatus). J Androl. 2004:25:872-80.

30. Zappacosta F, Scott GF, Huddleston MJ, Annan RS. An optimized platform for hydrophilic interaction chromatographyimmobilized metal affinity chromatography enables deep coverage of the rat liver phosphoproteome. J Proteome Res. 2015;14:997-1009.

31. Distler U, Kuharev J, Navarro P, Tenzer S. Label-free quantification in ion mobility-enhanced data-independent acquisition proteomics. Nat Protoc. 2016;11:795-812.

32. Mi H, Huang X, Muruganujan A, Tang H, Mills C, Kang D, et al. PANTHER version 11: expanded annotation data from Gene Ontology and Reactome pathways, and data analysis tool enhancements. Nucleic Acids Res. 2017;45:D183-D189.

33. Szklarczyk D, Franceschini A, Wyder S, Forslund K, Heller D, Huerta-Cepas J, et al. STRING v10: protein-protein interaction networks, integrated over the tree of life. Nucleic Acids Res. 2015;43:D447-52.

34. Uhlen M, Bandrowski A, Carr S, Edwards A, Ellenberg J, Lundberg E, et al. A proposal for validation of antibodies. Nat Methods. 2016;13:823-7.

35. Eisenberg ML, Kim S, Chen Z, Sundaram R, Schisterman EF, Buck Louis GM. The relationship between male BMI and waist circumference on semen quality: data from the LIFE study. Hum Reprod. 2014;29:193-200.

36. Ramírez-Torres MA, Carrera A, Zambrana M. [High incidence of hyperestrogenemia and dyslipidemia in a group of infertile men]. Ginecol Obstet Mex. 2000;68:224-9.

37. Lu J-C, Jing J, Yao Q, Fan K, Wang G-H, Feng R-X, et al. Relationship between lipids levels of serum and seminal plasma and semen parameters in 631 Chinese subfertile men. PLoS ONE. 2016;11:e0146304.

38. Rato L, Alves MG, Cavaco JE, Oliveira PF. High-energy diets: a threat for male fertility? Obes Rev. 2014;15:996-1007. 
39. Morgan DH, Ghribi O, Hui L, Geiger JD, Chen X. Cholesterolenriched diet disrupts the blood-testis barrier in rabbits. Am $\mathrm{J}$ Physiol Endocrinol Metab. 2014;307:E1125-30.

40. Cheng CY, Mruk DD. The blood-testis barrier and its implications for male contraception. Pharmacol Rev. 2012;64:16-64.

41. Yan HHN, Mruk DD, Wong EWP, Lee WM, Cheng CY. An autocrine axis in the testis that coordinates spermiation and bloodtestis barrier restructuring during spermatogenesis. Proc Natl Acad Sci USA. 2008;105:8950-5.

42. Wang Q, Patton WF, Chiang ET, Hechtman HB, Shepro D. Filamin translocation is an early endothelial cell inflammatory response to bradykinin: regulation by calcium, protein kinases, and protein phosphatases. J Cell Biochem. 1996;62:383-96.

43. Su W, Mruk DD, Lie PPY, Lui W-Y, Cheng CY. Filamin A is a regulator of blood-testis barrier assembly during postnatal development in the rat testis. Endocrinology. 2012;153:5023-35.

44. Feng Y, Chen MH, Moskowitz IP, Mendonza AM, Vidali L, Nakamura F, et al. Filamin A (FLNA) is required for cell-cell contact in vascular development and cardiac morphogenesis. Proc Natl Acad Sci USA. 2006;103:19836-41.

45. Castoria G, D'Amato L, Ciociola A, Giovannelli P, Giraldi T, Sepe L, et al. Androgen-induced cell migration: role of androgen receptor/filamin A association. PLoS ONE. 2011;6:e17218.

46. Adams M, Simms RJ, Abdelhamed Z, Dawe HR, Szymanska K, Logan CV, et al. A meckelin-filamin A interaction mediates ciliogenesis. Hum Mol Genet. 2012;21:1272-86.

47. Mollet G, Silbermann F, Delous M, Salomon R, Antignac C, Saunier S. Characterization of the nephrocystin/nephrocystin-4 complex and subcellular localization of nephrocystin-4 to primary cilia and centrosomes. Hum Mol Genet. 2005;14:645-56.

48. Alazami AM, Alshammari MJ, Baig M, Salih MA, Hassan HH, Alkuraya FS. NPHP4 mutation is linked to cerebello-oculo- renal syndrome and male infertility. Clin Genet. 2014;85:371-5.

49. Ozanne DM, Brady ME, Cook S, Gaughan L, Neal DE, Robson CN. Androgen receptor nuclear translocation is facilitated by the f-actin cross-linking protein filamin. Mol Endocrinol. 2000;14:1618-26.

50. Loy CJ, Sim KS, Yong EL. Filamin-A fragment localizes to the nucleus to regulate androgen receptor and coactivator functions. Proc Natl Acad Sci USA. 2003;100:4562-7.

51. Willems A, De Gendt K, Allemeersch J, Smith LB, Welsh M, Swinnen JV, et al. Early effects of Sertoli cell-selective androgen receptor ablation on testicular gene expression. Int $\mathbf{J}$ Androl. 2010;33:507-17.

52. Kuwahara S, Ikei A, Taguchi Y, Tabuchi Y, Fujimoto N, Obinata $\mathrm{M}$, et al. PSPC1, NONO, and SFPQ are expressed in mouse Sertoli cells and may function as coregulators of androgen receptor-mediated transcription. Biol Reprod. 2006;75:352-9.

53. Major AT, Hogarth CA, Miyamoto Y, Sarraj MA, Smith CL, Koopman $\mathrm{P}$, et al. Specific interaction with the nuclear transporter importin $\alpha 2$ can modulate paraspeckle protein 1 delivery to nuclear paraspeckles. Mol Biol Cell. 2015;26:1543-58.

54. Shi H-J, Wu AZ, Santos M, Feng Z-M, Huang L, Chen Y-M, et al. Cloning and characterization of rat spermatid protein SSP411: a thioredoxin-like protein. J Androl. 2004;25:479-93.

55. Liu M, Ru Y, Gu Y, Tang J, Zhang T, Wu J, et al. Disruption of Ssp411 causes impaired sperm head formation and male sterility in mice. Biochim Biophys Acta Gen Subj. 2018;1862:660-8.

56. Mallidis C, Agbaje I, O'Neill J, McClure N. The influence of type 1 diabetes mellitus on spermatogenic gene expression. Fertil Steril. 2009;92:2085-7.

57. Zhang F, Sun W, Chen J, Jiang L, Yang P, Huang Y, et al. SREBP-2, a new target of metformin? Drug Des Devel Ther. 2018;12:4163-70. 